\title{
The influence of gender concordance between general practitioner and patient on antibiotic prescribing for sore throat symptoms: a retrospective study
}

\author{
D. Eggermont ${ }^{1 *+}$ D, M. A. M. Smit ${ }^{1 \dagger}$, G. A. Kwestroo ${ }^{1 \dagger}$, R. A. Verheij ${ }^{2}$, K. Hek $^{2}$ and A. E. Kunst ${ }^{1}$
}

\begin{abstract}
Background: Patient gender as well as doctor gender are known to affect doctor-patient interaction during a medical consultation. It is however not known whether an interaction of gender influences antibiotic prescribing. This study examined GP's prescribing behavior of antibiotics at the first presentation of patients with sore throat symptoms in primary care. We investigated whether GP gender, patient gender and gender concordance have an effect on the GP's prescribing behavior of antibiotics in protocolled and non-protocolled diagnoses.

Methods: We analyzed electronic health record data of 11,285 GP practice consultations in the Netherlands in 2013 extracted from the Nivel Primary Care Database. Our primary outcome was the prescription of antibiotics for throat symptoms. Sore throat symptoms were split up in 'protocolled diagnoses' and 'non-protocolled diagnoses'. The association between gender concordance and antibiotic prescription was estimated with multilevel regression models that controlled for patient age and comorbidity.

Results: Antibiotic prescription was found to be lower among female GPs (OR 0.88, Cl 95\% 0.67-1.09; $p=.265$ ) and female patients (OR 0.93,95\% 0.84-1.02; $p=.142$ ), but observed differences were not statistically significant. The difference in prescription rates by gender concordance were small and not statistically significant in non-protocolled consultations (OR 0.92, OR 95\% Cl: 0.83-1.01; $p=.099$ ), protocolled consultations (OR 1.00, OR 95\% Cl: 0.68-1.32; $p=.996$ ) and all GP practice consultations together (OR 0.92, OR 95\% Cl: 0.82-1.02; $p=.118$ ). Within the female GP group, however, gender concordance was associated with reduced prescribing of antibiotics (OR 0.85, OR 95\% Cl: 0.72-0.99; $p=0.034$ ).

Conclusions: In this study, female GPs prescribed antibiotics less often than male GPS, especially in consultation with female patients. This study shows that, in spite of clinical guidelines, gender interaction may influence the prescription of antibiotics with sore throat symptoms.
\end{abstract}

Keywords: Gender role, Anti-bacterial agents, Drug resistance, Prescriptions, Sore throat, General practitioner

\section{Background}

Bacterial resistance is an important topic in today's health policy [1]. Although growing microbacterial resistance is partly a natural process, it can be accelerated with the inappropriate prescription of antibiotics by health care professionals [2]. With this in mind, factors which influence

\footnotetext{
* Correspondence: d.eggermont@amc.uva.nl

${ }^{\dagger}$ D. Eggermont, Smit MAM and G. A. Kwestroo contributed equally to this work.

'Department of Public Health, Amsterdam UMC, University of Amsterdam, Meibergdreef 9, Amsterdam 1105, AZ, the Netherlands

Full list of author information is available at the end of the article
}

the prescription of antibiotics, other than patient's clinical presentation, became an object of study. Indeed, research suggests the importance of such non-medical factors. General practitioners' (GPs) attitudes such as fear and complacency affect prescribing behavior [3, 4]. Akkerman showed that physicians with more years of practice were more likely to prescribe antibiotics, especially if they felt they had little time per patient [5]. Moreover, GP's perception of patients' expectations concerning medication prescription influences the actual prescribing behavior [6-8]. Overall, these studies imply that doctor-patient interaction

(c) The Author(s). 2018 Open Access This article is distributed under the terms of the Creative Commons Attribution 4.0 International License (http://creativecommons.org/licenses/by/4.0/), which permits unrestricted use, distribution, and 
has an important influence on antibiotic prescribing behavior.

When focusing on the doctor-patient relationship, the gender of both the doctor and patient are known to influence their interaction $[9,10]$. Among others, the GP's gender may determine the communication style, the contents of the consultation, which drugs are indicated and whether they are prescribed [11-13]. In turn, the gender of the patient also affects the interaction between doctor and patient. For example, female patients are more likely to express their emotions during the consultation [14] and had fewer discussions about addictive behavior or heart disease risk $[9,15]$. This implies that GPs might make medical decisions which are affected by gender-related considerations and gender stereotypes.

Since both patient's and doctor's gender play a part in the medical process, it is not unlikely that the combination of a patient and doctor of the same gender (compared to dyads of opposite gender) may have additional effects. In interactions between patient and doctor, four gender dyads can be distinguished (male-male, female-female, male-female, female-male) of which two are concordant and two are discordant. It has been found that female-female consultations contain more affective talk and less analytical talk. The opposite occurs in male-male consultations [16]. Moreover, it appears that female concordance leads to communication that is most patient centered [17, 18], which may enhance health outcomes by elevated patients' trust, improved communication and patient satisfaction. Indeed, female gender concordance is associated with more effective treatment of cardiovascular risks [19] and male gender concordance is positively associated with measures on diet, nutrition and exercise counseling [20]. It is however not known whether gender concordance influences prescribing behavior of antibiotics. Possibly, concordance is an additional non-medical factor that affects (inappropriate) antibiotics prescription. Creating awareness of such non-medial factors could result in GPs being less biased, more objective and consistent in their treatments.

Since the 1980's there is an increase in the extent to which primary care practice is influenced by clinical guidelines [21]. For example, some diagnoses are followed by guidelines that leave the physician room to follow a treatment of choice ('non-protocolled' guidelines). Other diagnoses have guidelines in which a 'protocolled' treatment (e.g. antibiotic prescription) is strongly recommended. The power of a clinical guideline is to make sure the patient gets the most effective, evidence-based treatment. A guideline also reduces the variation in treatment for the same diagnoses between GPs.

In this study, we will explore whether the prescription of antibiotics depends on the patients or physicians gender and/or on their gender interaction (concordance). To do this, we will study prescribing behavior concerning patients presenting sore throat symptoms in primary care. This patient group was chosen since the inappropriate prescription of antibiotics is very common in sore throat symptoms [22] and because the majority of antibiotic prescriptions in The Netherlands is issued in primary care [23]. In addition, we will investigate whether gender concordance is less influential in diagnoses corresponding to a strong antibacterial protocol than in diagnoses that leave the GP more room for interpretation and choice.

\section{Methods}

The specific objectives of this study were to explore:

1. whether the likelihood that patients will be given a medical prescription depends on the gender of, respectively, the patient and the GP.

2. whether this likelihood depends on the gender concordance between patient and GP, with distinction between male-male and female-female concordance.

3. the role of gender and of gender concordance for prescription policy in non-protocolled guidelines and protocolled guidelines.

\section{Data source}

The electronic health records for this study were provided by the Netherlands Institute for Health Services Research (Nivel) Primary Care Database, containing GP practice consultations from 2013. We included general practices that registered information on the function and sex of caregiver. Moreover, the data included information on consultations, prescriptions (coded according to the Anatomical Therapeutical Chemical (ATC) classification) and diagnosis (coded according to the International Classification of Primary Care (ICPC) version 1) [24]. These consultations were handled by health professionals of whom 225, according to information provided by the practice, were known to be trained as GP. Other health professionals were for example physiotherapist, physician assistant, dietician or practice nurse. We used data from 22,412 GP practice consultations concerning patients with sore throat symptoms.

\section{Variables}

The electronic health records data contained information on: prescription of antibiotics (did or did not prescribe a medicine with ATC-code J01, which are antibiotics for systemic use), sex of both patient and caregiver, age of patient, function of caregiver (e.g. physiotherapist, physician assistant, dietician, nurse etc.), comorbidity (did or did not suffer from one or more 
chronic disease according to the GP's medical file) and ICPC-code. The ICPC classification system is used to record diagnosis and/or symptoms. This study focuses on ICPC codes relating to sore throat symptoms (see Table 1). Using the ICPC code, we distinguished between diagnoses based on symptoms versus those based on underlying pathology. ICPC-codes R21 and R22 represent symptoms (e.g. coughing) indicating that at the time of the consultation no real diagnosis (e.g. tonsillitis) was apparent.

We also measured whether the disease was 'protocolled'. For this, the ICPC code R76 (acute tonsillitis/ peritonsillar abscess) was regarded as protocolled. The Dutch GP guideline for acute sore throat complaints firmly advises to prescribe antibiotics for this diagnosis [25]. Other ICPC-codes related to sore throat were classified as non-protocolled, i.e. antibiotics are not indicated. To determine the presence of an antibiotic treatment protocol, the GP guideline was analyzed independently by three coders. Intercoder agreement was $100 \%$, as all coders regarded the same ICPC-codes as either 'protocolled' and 'non-protocolled'.

\section{Exclusion criteria}

The following exclusion criteria were used to select patients and GP practice consultations for the analyses:

1. This study focuses on the gender interaction between patient and GP in the general practice. Hence, all practice consultations with other health care professionals within the practice (e.g. medical student, physician assistant, dietician, etc.) were excluded.

2. In the communication between a GP and a child, parents are usually involved [26]. Consequently, the

Table 1 Diagnoses for sore throat symptoms

\begin{tabular}{lllll}
\hline $\begin{array}{l}\text { ICPC- } \\
\text { code }\end{array}$ & Diagnoses & $\begin{array}{l}\text { Percentage of all } \\
\text { consultations } \\
(n=11,285)\end{array}$ & Protocolled & $\begin{array}{l}\text { Symptoms/ } \\
\text { no diagnosis }\end{array}$ \\
\hline R21 & $\begin{array}{l}\text { Symptoms/ } \\
\text { complaints } \\
\text { throat }\end{array}$ & $19.8 \%$ & No & Yes \\
R22 & $\begin{array}{l}\text { Symptoms/ } \\
\text { complaints } \\
\text { tonsils }\end{array}$ & $1.0 \%$ & No & Yes \\
R72 & $\begin{array}{l}\text { Streptococcus/ } \\
\text { scarlet fever }\end{array}$ & $1.3 \%$ & No & No \\
R74 & $\begin{array}{l}\text { Acute infection } \\
\text { upper airway }\end{array}$ & $67.4 \%$ & No & No \\
R76 & $\begin{array}{l}\text { Acute tonsillitis/ } \\
\text { peritonsillar } \\
\text { abscess }\end{array}$ & $8.5 \%$ & Yes & No \\
R77 & $\begin{array}{l}\text { Acute laryngitis/ } \\
\text { tracheitis }\end{array}$ & $1.9 \%$ & No & No \\
\hline
\end{tabular}

gender interaction between child and GP is complicated by the gender of the parent that is present during the consultation. Therefore, all children (age 0 to 17) were excluded from the study.

3. At first presentation, all treatment options are still possible and patient-doctor interaction may be decisive for prescription. Therefore, we decided to focus on first consultations, which implied that all second and consecutive practice consultations in 2013 for sore throat symptoms were excluded.

\section{Descriptives and demographics}

After selecting only the practice consultations handled by a GP, 20511 (91.5\%) consultations were available for analysis (see Fig. 1). The second exclusion criterion (only 18+ patients) brought our dataset back from 20,511 to 12,523 (61.1\%) consultations. Finally, after applying our last exclusion criterion (only first presentation), 11,285 (55.0\%) first consultations, handled by 225 GPs, remained for analysis.

\section{Statistical analyses}

Logistic regression was performed to calculate the effect of our main predictors on our outcome variable 'prescription of antibiotics' (dichotomous). In the regression model, our main predictors for antibiotic prescription were patient gender, GP gender and concordance. Patient's age and comorbidity were added as control variables. We also tested whether GP's gender and gender concordance had an interaction effect by creating an interaction term and adding this to the regression model along with its constituting variables. In addition, in further analyses, the regression models were calculated separately for protocolled and nonprotocolled prescriptions. In order to explore whether the main predictors have different effects on male and female GP's, the regression models were also calculated separately for male and female GP's consultations.

Due to clustering of observations at the level of GPs and health practices, we applied multi-level models. In a generalized linear mixed model, we entered three different data levels: [1] practice, [2] GP and [3] patient. All analyses were performed with statistical package SPSS versions 22 .

\section{Privacy}

Dutch law allows the use of electronic health records for research purposes under certain conditions. According to the legislation, neither obtaining informed consent from patients nor approval by a medical ethics committee is obligatory for this type of observational studies containing no directly identifiable data [27]. This study has been approved by the applicable governance bodies of NIVEL Primary Care Database under number NZR-00315.025. 


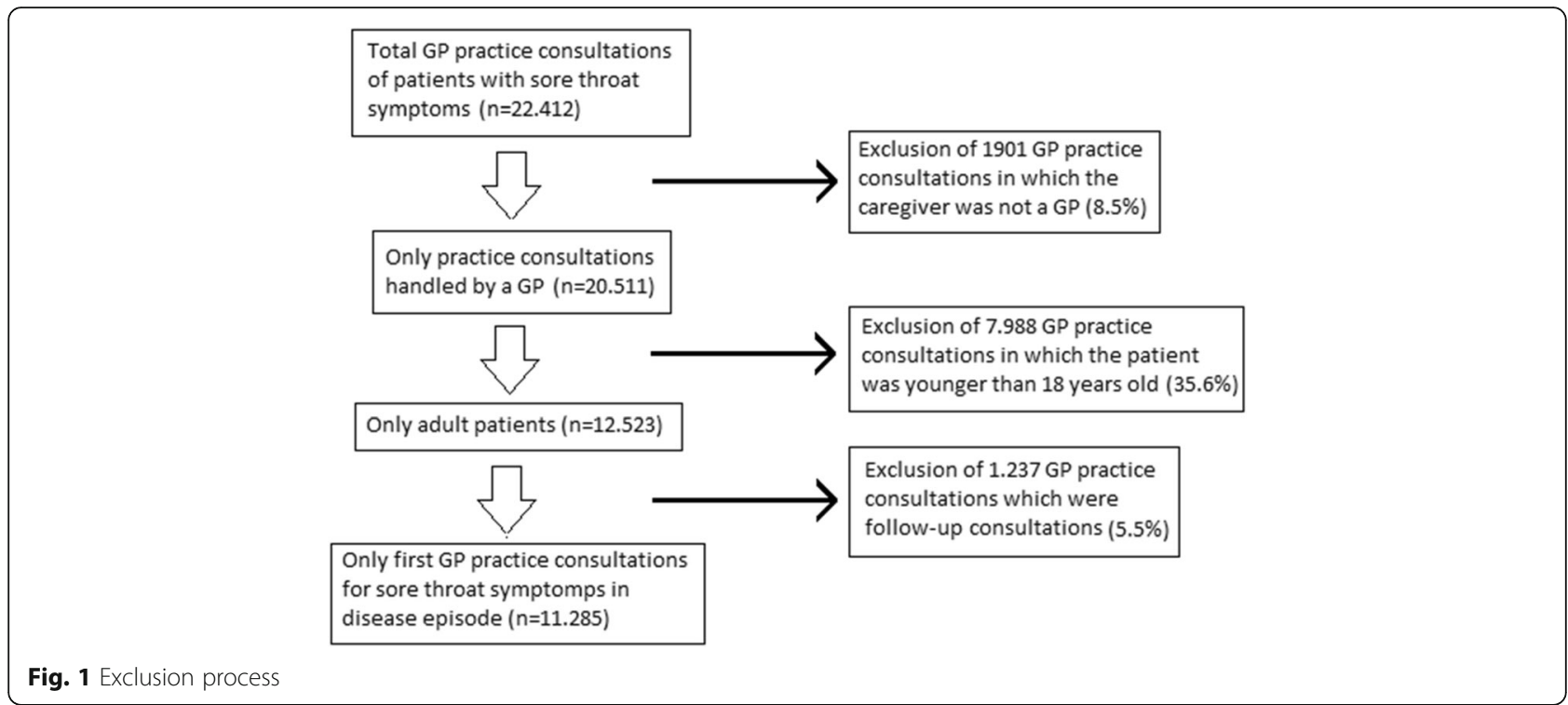

\section{Results}

Of all GP practice consultations, $52.1 \%$ were handled by male GPs. In $39.2 \%$ of the consultations the patient was male. Of all cases $27.6 \%$ of the patients were prescribed antibiotics. The concordant dyads are represented with $52.8 \%$ of the consultations, while $47.2 \%$ of the consultations contained discordant couples. For all consultations, $8.5 \%$ got assigned an ICPC code labeled as protocolled and $91.5 \%$ as non-protocolled.

Table 2 shows that patient age, presence of comorbidity and the amount of consultations without a real diagnosis were similar in consultations with male and female GPs. Male GPs prescribed antibiotics in $29.5 \%$ of their consultations. Female GPs did so in $25.7 \%$ of their consultations. For female GPs, $64.1 \%$ of their consultations were concordant (i.e. with a female patients), while male GPs had same-sex consultations in $42.3 \%$ of their consultations. The concordant couples had an antibiotic prescription rate of $26.8 \%$ of the consultations, against $28.6 \%$ in discordant couples.

Figure 2 shows the percentage of antibiotics prescribed per gender dyad. In accordance with Table 2, it illustrates that female GPs prescribe less antibiotics than male GPs. Female GPs especially prescribe less antibiotics for female patients $(24.8 \%$ in concordant couples versus $27.3 \%$ in discordant couples). In consultations

Table 2 Descriptive of patients seen by male GP vs female GP and concordant vs discordant couples

\begin{tabular}{|c|c|c|c|c|}
\hline & Male GP & Female GP & Concordant & Discordant \\
\hline Sample size & 5956 & 5329 & 5956 & 5329 \\
\hline Average age patient (years) & 46.7 & 46.3 & 46.6 & 46.4 \\
\hline Comorbidity patient & $53.6 \%$ & $52.5 \%$ & $53.3 \%$ & $52.7 \%$ \\
\hline Concordance & $42.3 \%$ & $64.1 \%$ & - & - \\
\hline Symptoms / no diagnosis & $20.3 \%$ & $21.4 \%$ & $21.5 \%$ & $20.1 \%$ \\
\hline Protocolled diagnoses & $7.9 \%$ & $9.1 \%$ & $8.4 \%$ & $8.6 \%$ \\
\hline \multicolumn{5}{|l|}{ Antibiotics prescribed } \\
\hline All diagnoses & $29.5 \%$ & $25.7 \%$ & $26.8 \%$ & $28.6 \%$ \\
\hline -Male GP & - & - & $29.6 \%$ & $29.4 \%$ \\
\hline -Female GP & - & - & $24.8 \%$ & $27.3 \%$ \\
\hline In non-protocolled diagnoses & $25.6 \%$ & $21.5 \%$ & $22.8 \%$ & $24.6 \%$ \\
\hline -Male GP & - & - & $25.8 \%$ & $25.5 \%$ \\
\hline -Female GP & - & - & $20.7 \%$ & $23.0 \%$ \\
\hline In protocolled diagnoses & $74.1 \%$ & $67.3 \%$ & $69.7 \%$ & $71.7 \%$ \\
\hline -Male GP & - & - & $76.9 \%$ & $72.3 \%$ \\
\hline -Female GP & - & - & $65.5 \%$ & $70.7 \%$ \\
\hline
\end{tabular}




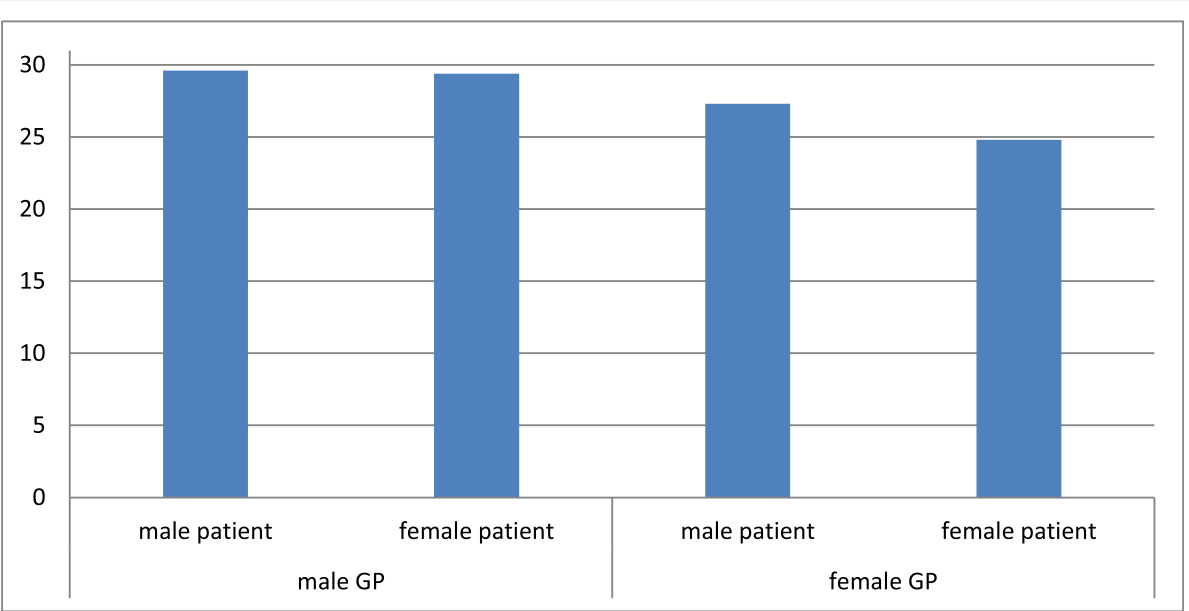

Fig. 2 Percentage of consultations for sore throat symptoms with antibiotic prescription. Female GP's prescribe antibiotics less often than male GP's $(p=.000)$. In dyads with a female GP, antibiotics are less often prescribed when there is gender concordance $(p=.044)$

with male GPs, on the other hand, there is no such difference (concordant couples $29.6 \%$ versus $29.4 \%$ in discordant couples).

Table 3 shows the outcome of the multilevel regression analysis. In the total population, concordance (OR 0.92, OR

Table 3 Predictors for antibiotic prescription after multi-level analysis $^{a}$

\begin{tabular}{lcccc}
\hline & Exp (B) & Lower & Upper & Significance \\
\hline All GP practice consultations $(n=11,285)^{\mathrm{b}}$ & & \\
Concordance & 0.92 & 0.83 & 1.01 & $p=.099$ \\
Gender GP & 0.88 & 0.67 & 1.09 & $p=.265$ \\
Gender patient & 0.93 & 0.84 & 1.02 & $p=.142$ \\
Comorbidity & 1.09 & 0.99 & 1.18 & $p=.090$ \\
Age patient & 1.00 & 1.00 & 1.00 & $p=.022$ \\
Non-protocolled $(n=10,328)^{\mathrm{C}}$ & & & \\
Concordance & 0.92 & 0.82 & 1.02 & $p=.118$ \\
Gender GP & 0.83 & 0.58 & 1.08 & $p=.180$ \\
Gender patient & 0.96 & 0.85 & 1.06 & $p=.404$ \\
Comorbidity & 1.21 & 1.01 & 1.32 & $p=.000$ \\
Age patient & 1.00 & 0.99 & 1.00 & $p=.000$ \\
Protocolled $(n=957)^{\mathrm{d}}$ & & & & \\
Concordance & 1.00 & 0.68 & 1.32 & $p=.996$ \\
Gender GP & 0.65 & 0.26 & 1.04 & $p=.076$ \\
Gender patient & 0.79 & 0.47 & 1.10 & $p=.184$ \\
Comorbidity & 0.92 & 0.57 & 1.26 & $p=.633$ \\
Age patient & 0.98 & 0.96 & 0.99 & $p=.002$ \\
\hline
\end{tabular}

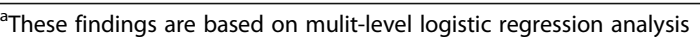

${ }^{\mathrm{b}}$ There was no interaction effect of concordance and gender GP $(p=.225)$

${ }^{c}$ There was no interaction effect of concordance and gender GP $(p=.272)$

${ }^{\mathrm{d}}$ There was no interaction effect of concordance and gender GP $(p=.145)$
95\% CI: 0.83-1.01), female GP (OR 0.88, 95\% Cl: 0.67-1.09) and female patient (OR 0.93, 95\% Cl: 0.84-1.02) show lower rates of antibiotic prescription, however not with statistical significance. Similar results were found in both types of prescriptions (protocolled and non-protocolled). Patient age was significantly associated with antibiotics prescription (OR 1.00, 95\% CI: $1.00-1.00)$. This was equally true for protocolled and non-protocolled consultations. Comorbidity was a significant predictor in non-protocolled consultations (OR 1.21, 95\% CI: 1.01-1.32), but not in the protocolled consultations (OR 0.92, 95\% CI: 0.57-1.26).

Table 4 shows that for female GPs concordance is associated with antibiotic prescription after controlling for comorbidity and patient age. In female concordant consultations less antibiotics were prescribed (OR 0.85, 95\% CL: 0.72-0.99). The lower section of Table 4 shows that for male GPs concordance is not associated with antibiotic prescription after controlling for comorbidity and patient age (OR 0.99, 95\% CL: 0.86-1.11).

\section{Discussion}

\section{Summary of results}

In this study, we assessed whether gender concordance between GP and patient was associated with antibiotics prescribing. Gender concordance among females is associated with less prescription of antibiotics, i.e. female GPs appear to issue fewer antibiotics prescriptions to female patients than to male patients. Concordance appears not to have a similar effect in prescribing behavior of male GPs. For both concordant dyads combined, prescription rates were lower than for discordant dyads, but this difference was not statistically significant. Whether the treatment was protocolled did not appear to affect these findings. 
Table 4 The model of predictors for antibiotic prescription according to gender of GPa

\begin{tabular}{|c|c|c|c|c|c|c|c|c|}
\hline & \multicolumn{4}{|c|}{ Practice consultations with female GP $(n=5410)$} & \multicolumn{4}{|c|}{ Practice consultations with male GP $(n=5875)$} \\
\hline & $\operatorname{Exp}(B)$ & Lower & Upper & Significance & $\operatorname{Exp}(B)$ & Lower & Upper & Significance \\
\hline Concordance & 0.85 & 0.72 & 0.99 & $p=.034$ & 0.99 & 0.86 & 1.11 & $p=.827$ \\
\hline Comorbidity & 1.16 & 1.02 & 1.31 & $p=.028$ & 1.02 & 0.89 & 1.16 & $p=.731$ \\
\hline Age patient & 1.00 & 1.00 & 1.01 & $p=.063$ & 1.00 & 1.00 & 1.00 & $p=.193$ \\
\hline
\end{tabular}

${ }^{\text {a }}$ These findings are based on mulit-level logistic regression analysis

\section{Interpretation of results}

When a patient with sore throat symptoms presents him- or herself in a primary care facility, infection is usually the underlying cause [28]. For these symptoms, physicians can send their patient home for a 'wait and see' policy or they can prescribe antibiotics. The results of this study indicate that female physicians are more likely to apply a wait and see policy when seeing a female patient in comparison with the other gender dyads.

Female concordance has been associated with a communication style that is more patient centered [17, 18]. Patient centered communication enhances health outcomes by elevated patients' trust, improved communication and patient satisfaction [17-20, 29]. When communication is patient centered, the physician focuses at hearing and understanding the patients' perspectives. For this, the physician needs to explore the patients ideas and concerns as well as their expectations regarding the physician [30]. It has been shown that addressing patients' ideas, concerns and expectations during a consultation, known as the ICE-model, might lead to fewer medication prescriptions [31]. This is potentially important because a wait and see policy is easier to adopt when patients feel being heard.

In our study, $27.6 \%$ of all patients got prescribed antibiotics for their sore throat complaints. This is low in comparison to other countries. In the UK, for example, approximately $56 \%$ of all patients with sore throat complaints receive antibiotics from their GP [32]. Traditionally, antibiotic prescription in the Netherlands is lowest of all European countries, with differences up to a threefold [33]. It is unclear how this relates to the outcomes of our study. Therefore, generalizing our findings to countries with much higher antibiotic prescription rate should be done with caution.

Patient age and comorbidity were identified as being predictive for prescribing antibiotics. This was in line with previous research which showed age to be a determinant in the prescription of antibiotics for lower respiratory tract infections and that antibiotics are more often prescribed for patients with comorbidity such as diabetes or chronic obstructive pulmonary disease [34].

\section{Limitations of the study}

This study was performed with electronic health records data that were routinely recorded in general practices. This type of data has advantages and disadvantages. Advantages are that the data is cheap, readily available and can be assumed in many respects to represent what actually takes place in clinical practice. However, it also means that circumstances, habits and customs of individual practices in the way data are recorded, can have an impact on the quality of the data [35]. In this study this may have contributed to the fact that we had to exclude $8.5 \%$ of all consultations. These consultations had to be excluded because these consultations did not appear to have taken place with the GP but with other practice personnel. The percentage of consultations with the GP is likely to be an underestimate. Some of the consultations may have been taken care of by the GP, but recorded by a practice assistant.

In this study, we would have liked to include age of the GP. It has been shown that the years of experience of the GP correlates with antibiotics prescription [5]. Because, on average, male GPs are older than female GPs [36], age might have been a confounder in this study. Another limitation is that we could not include information on patients' expectations and concerns, which might also influence prescribing behavior [31].

Although the existence of comorbidity was reported by the GP, in this study we regarded comorbidities as present or non-present and did not investigate the role of individual comorbidities. However, COPD and diabetes are examples of diseases which affect susceptibility to disease and therefore possibly influence the prescribing behavior of the GP to a greater extent than most other diseases. In future research it would be important to include these comorbidities separately.

The current study focused solely on sore throat. Therefore, generalizing our findings to other complaints or symptoms should be done with caution. Future research should assess for a broader spectrum of symptoms whether prescription rates are related to gender concordance. Also, sore throat symptoms can be considered relatively gender neutral. This would be different when for example urogenital symptoms were concerned. This could change the effect of gender concordance. 
Further research could focus on the effect of gender concordance on antibiotics.

\section{Implications of this study}

In recent years the medical community in western societies has experienced a growth in number of female physicians [36]. The results of this study suggest that this feminization could lead to a reduction in the prescription of antibiotics. Female concordance enhances patient centred communication and this might be the underlying explanation for our findings. If so, our results underline the importance of effective communication styles, both by male and female GPs, to contain the prescription of antibiotics.

\section{Conclusion}

In this study, we found that gender concordance among females is associated with less prescription of antibiotics for sore throat complaints. In other words, female GPs appear to issue fewer antibiotics prescriptions to female patients than to male patients. Among male GPs, concordance did not appear to have a similar effect. Possibly, our findings can be explained by a different communication style that is handled by female GPs, especially when attending with female patients. Future studies should aim to describe and understand female concordance in more detail, since the findings may suggest that training doctors to adjust their communication style could prevent the prescription of unnecessary antibiotics.

\section{Abbreviations}

ATC: Anatomical therapeutical chemical; GP: General Practitioner; ICPC: International classification of primary care; Nivel: Netherlands institute for health services research

\section{Acknowledgments}

Not applicable.

\section{Funding}

The financial resources required for the publication of this study were made available by UVA-AMC and Nivel.

\section{Availability of data and materials}

The data that support the findings of this study are available from NIVEL, but restrictions apply to the availability of these data, which were used under license for the current study, and so are not publicly available. Data are however available from the authors upon reasonable request and with permission of NIVEL.

\section{Authors' contributions}

DE, MAMS and GAK wrote the study proposal, analyzed and interpreted the patient data and were the main authors of the manuscript. AK supervised the research project, contributed to the text of the manuscript and was also a major contributor to the study design. RV and $\mathrm{KH}$ contributed to the design of the study and the text of the manuscript. AK, RV and $\mathrm{KH}$ critically reviewed consecutive draft versions of the manuscript. All authors read and approved the final manuscript.

\section{Authors' information}

DE has a master in communications and is currently a medical student in his master phase at the University of Amsterdam - Academic Medical Centre.
MAMS is a medical student in his master phase at the University of Amsterdam - Academic Medical Centre.

GAK is a medical student in his master phase at the University of Amsterdam - Academic Medical Centre.

AK is a professor in social epidemiology and head of the Department of Public Health at the University of Amsterdam - Academic Medical Centre. RV is programme leader "Big Data \& Learning health systems" at the Netherlands Institute for Health Services Research (NIVEL).

$\mathrm{KH}$ is postdoctorate researcher at the Netherlands Institute for Health Services Research (NIVEL).

\section{Ethics approval and consent to participate}

Dutch law allows the use of electronic health records for research purposes under certain conditions. According to the legislation, neither obtaining informed consent from patients nor approval by a medical ethics committee is obligatory for this type of observational studies containing no directly identifiable data [27]. This study has been approved by the applicable governance bodies of NIVEL Primary Care Database under number NZR00315.025

Consent for publication

Not applicable

\section{Competing interests}

The authors declare that they have no competing interests.

\section{Publisher's Note}

Springer Nature remains neutral with regard to jurisdictional claims in published maps and institutional affiliations.

\section{Author details}

${ }^{1}$ Department of Public Health, Amsterdam UMC, University of Amsterdam, Meibergdreef 9, Amsterdam 1105, AZ, the Netherlands. ${ }^{2}$ Netherlands Institute for Health Services Research (Nivel), Otterstraat 118-124, Utrecht 3513, CR, the Netherlands.

Received: 6 December 2017 Accepted: 19 October 2018

Published online: 17 November 2018

References

1. Prestinaci F, Pezzotti P, Pantosti A. Antimicrobial resistance: a global multifaceted phenomenon. Pathogens and global health. 2015;109(7):309-18.

2. Costelloe C, Metcalfe C, Lovering A, Mant D, Hay AD. Effect of antibiotic prescribing in primary care on antimicrobial resistance in individual patients: systematic review and meta-analysis. BMJ. 2010;340:c2096.

3. Vazquez-Lago JM, Lopez-Vazquez P, López-Durán A, Taracido-Trunk M, Figueiras A. Attitudes of primary care physicians to the prescribing of antibiotics and antimicrobial resistance: a qualitative study from Spain. Fam Pract. 2012;29(3):352-60.

4. Teixeira Rodrigues A, Roque F, Falcao A, Fiqueiras A, Herdeiro MT Understanding physician antibiotic prescribing behaviour: a systematic review of qualitative studies. Int J Antimicrob Agents. 2013:41(3):203-12.

5. Akkerman AE, Kuyvenhoven MM, van der Wouden JC, Verheij TJ. Prescribing antibiotics for respiratory tract infections by GPS: management and prescriber characteristics. Br J Gen Pract. 2005:55(511):114-8.

6. Lado E, Vacariza M, Fernandez-Gonzalez C, Gestal-Otero JJ, Figueiras A. Influence exerted on drug prescribing by patients' attitudes and expectations and by doctors' perception of such expectations: a cohort and nested case-control study. J Eval Clin Pract. 2008;14(3):453-9.

7. Altiner A, Knauf A, Moebes J, Sielk M, Wilm S. Acute cough: a qualitative analysis of how GPs manage the consultation when patients explicitly or implicitly expect antibiotic prescriptions. Fam Pract. 2004;21(5):500-6.

8. Coenen S, Francis N, Kelly M, Hood K, Nuttall J, Little P, et al. Are patient views about antibiotics related to clinician perceptions, management and outcome? A multi-country study in outpatients with acute cough. PLoS One. 2013:8(10):e76691.

9. Bertakis KD. The influence of gender on the doctor-patient interaction. Patient Educ Couns. 2009;76(3):356-60.

10. Adams A, Buckingham CD, Lindenmeyer A, McKinlay JB, Link C, Marceau L, et al. The influence of patient and doctor gender on diagnosing coronary heart disease. Sociology of health \& illness. 2008;30(1):1-18. 
11. Franks $P$, Bertakis KD. Physician gender, patient gender, and primary care. J Women's Health. 2003;12(1):73-80.

12. van den Brink-Muinen A. Sekseverschillen en de communicatie tussen huisarts en patiënt. Bijblijven. 2008;24:7-13.

13. Lagro-Janssen AL. Medicine is not gender-neutral: influence of physician sex on medical care. Ned Tijdschr Geneeskd. 2008;152(20):1141-5.

14. STEWART M. Patient characteristics which are related to the doctor-patient interaction. Fam Pract. 1984;1 (1):30-6.

15. Grunau GL, Ratner PA, Galdas PM, Hossain S. Ethnic and gender differences in patient education about heart disease risk and prevention. Patient Educ Couns. 2009;76(2):181-8.

16. Van den Brink-Muinen A, van Dulmen S, Messerli-Rohrbach V, Bensing J. Do gender-dyads have different communication patterns? A comparative study in Western-European general practices. Patient Educ Couns. 2002;48(3):253-64.

17. Sandhu H, Adams A, Singleton L, Clark-Carter D, Kidd J. The impact of gender dyads on doctor-patient communication: a systematic review. Patient Educ Couns. 2009;76(3):348-55.

18. Bertakis KD, Azari R. Patient-centered care: the influence of patient and resident physician gender and gender concordance in primary care. J Womens Health (Larchmt). 2012;21(3):326-33.

19. Schmittdiel JA, Traylor A, Uratsu CS, Mangione CM, Ferrara A, Subramanian $U$. The association of patient-physician gender concordance with cardiovascular disease risk factor control and treatment in diabetes. J Womens Health (Larchmt). 2009;18(12):2065-70.

20. Pickett-Blakely O, Bleich SN, Cooper LA. Patient-physician gender concordance and weight-related counseling of obese patients. Am J Prev Med. 2011;40(6):616-9.

21. Woolf SH, Grol R, Hutchinson A, Eccles M, Grimshaw J. Clinical guidelines: potential benefits, limitations, and harms of clinical guidelines. BMJ. 1999; 318(7182):527.

22. Dekker AR, Verheij TJ, van der Velden AW. Inappropriate antibiotic prescription for respiratory tract indications: most prominent in adult patients. Fam Pract. 2015;32(4):401-7.

23. Butler CC, Hillier S, Roberts Z, Dunstan F, Howard A, Palmer S. Antibiotic-resistant infections in primary care are symptomatic for longer and increase workload: outcomes for patients with E coli UTIs. Br J Gen Pract 2006:56(530):686-92.

24. Wood M, Lamberts H. International classification of primary care: prepared for the world organisation of national colleges, academies and academic associations of general practitioners/family physicians (WONCA) by the ICPC working party. Oxford: Oxford University Press; 1987.

25. NHG-Standaard Acuut hoesten 2011. [cited 2017]. Available from: https:// www.nhg.org/standaarden/volledig/nhg-standaard-acuut-hoesten.

26. Tates K, Meeuwesen L, Elbers E, Bensing J. I've come for his throat': roles and identities in doctor-parent-child communication. Child Care Health Dev. 2002;28(1):109-16.

27. Goossens H. Dutch Civil Law. Available from: http://www.dutchcivillaw.com/ civilcodebook077.htm

28. Zwart SDCF. Diagnostiek van alledaagse klachten. 3rd ed: BSL; 2011.

29. Schieber AC, Delpierre C, Lepage B, Afrite A, Pascal J, Cases C, et al. Do gender differences affect the doctor-patient interaction during consultations in general practice? Results from the INTERMEDE study. Fam Pract. 2014;31(6):706-13.

30. Hashim MJ. Patient-Centered Communication: Basic Skills. Am Fam Physician. 2017;95(1):29-34

31. Matthys J, Elwyn G, Van Nuland M, Van Maele G, De Sutter A, De Meyere M, et al. Patients' ideas, concerns, and expectations (ICE) in general practice: impact on prescribing. Br J Gen Pract. 2009;59(558):29-36.

32. Mehta N, Schilder A, Fragaszy E, H ERE, Dukes O, Manikam L, et al. Antibiotic prescribing in patients with self-reported sore throat. J Antimicrob Chemother. 2017;72(3):914-22.

33. Goossens H, Ferech M, Vander Stichele R, Elseviers M. Outpatient antibiotic use in Europe and association with resistance: a cross-national database study. Lancet (London, England). 2005;365(9459):579-87.

34. Bont J, Hak E, Birkhoff CE, Hoes AW, Verheij TJ. Is co-morbidity taken into account in the antibiotic management of elderly patients with acute bronchitis and COPD exacerbations? Fam Pract. 2007;24(4):317-22.

35. Verheii RA, Curcin V, Brendan BC, McGilchrist MM. Possible sources of Bias in primary care electronic health record data (re) use. J Med Internet Res. 2018; 20(5):e185

36. van der Velden LF, Hingstman L, Heiligers PJ, Hansen J. Increasing number of women in medicine: past, present and future. Ned Tijdschr Geneeskd. 2008;152(40):2165-71.

Ready to submit your research? Choose BMC and benefit from:

- fast, convenient online submission

- thorough peer review by experienced researchers in your field

- rapid publication on acceptance

- support for research data, including large and complex data types

- gold Open Access which fosters wider collaboration and increased citations

- maximum visibility for your research: over $100 \mathrm{M}$ website views per year

At $\mathrm{BMC}$, research is always in progress.

Learn more biomedcentral.com/submissions 